\title{
Literature Review on Motor Skill and Physical Activity in Preschool Children in New Zealand
}

\author{
Ajmol Ali1 ${ }^{*}$, Deborah Pigou ${ }^{1,2}$, Linda Clarke3, Claire McLachlan ${ }^{3,4}$ \\ ${ }^{1}$ School of Sport and Exercise, Massey University, Auckland, New Zealand \\ ${ }^{2}$ Harbour Sport, North Shore, Auckland, New Zealand \\ ${ }^{3}$ Institute of Education, Massey University, Auckland, New Zealand \\ ${ }^{4}$ Faculty of Education, Te Hononga School of Curriculum and Pedagogy, University of Waikato, Hamilton, New Zealand \\ Email: ${ }^{\star}$ A.Ali@massey.ac.nz
}

How to cite this paper: Ali, A., Pigou, D., Clarke, L., \& McLachlan, C. (2017). Literature Review on Motor Skill and Physical Activity in Preschool Children in New Zealand. Advances in Physical Education, 7, 1026.

https://doi.org/10.4236/ape.2017.71002

Received: December 22, 2016

Accepted: February 6, 2017

Published: February 9, 2017

Copyright () 2017 by authors and Scientific Research Publishing Inc. This work is licensed under the Creative Commons Attribution International License (CC BY 4.0).

http://creativecommons.org/licenses/by/4.0/

\begin{abstract}
Children's physical activity levels have decreased significantly over the past 20 - 30 years, coinciding with obesity rates reaching epidemic levels. There is little research into typically developing preschool (birth to 5 year-olds) children's physical activity, with the majority of research focusing on children at risk of motor skill or neurological deficiencies. This review examines current research into young children's development, especially motor development and physical activity, the effectiveness of intervention programmes for promoting children's physical development and the various methods used to assess physical development. A decrease in children's physical activity levels has coincided with an increase in obesity rates. Further research is needed to determine culturally and contextually appropriate and effective interventions for preschool children. Areas for further research include preschool children's physical activity, particularly in regards to movement guidelines and requirements for this age-group and ways to overcome potential barriers to meeting physical activity requirements. Young children's physical activity and motor skill proficiency may be an important predictor of later-life physically active behaviors. Physical literacy and physical activity interventions within early childhood education could potentially support academic skills as well as physical skills and behaviors.
\end{abstract}

\section{Keywords}

Physical Literacy, Physical Activity, Physical Education, Motor Skill

Development, Cognitive Development, Safety Skills

\section{Introduction}

Over the last 20 - 30 years, children's activity levels have decreased significantly, 
coinciding with obesity rates reaching epidemic levels (Gunner et al., 2005). This has led to an increase in the importance of health promotion and physical activity related research for preschool children (Gunner et al., 2005; Timmons et al., 2007; Robinson et al., 2015). Physical activity is associated with improving children's motor skill proficiency (Barnett et al., 2008; Sääkslahti et al., 2004) and, when they grow to adolescence, young children with better motor skill proficiency have $10 \%-20 \%$ higher chance of participating in vigorous physical activity (Barnett et al., 2009), enhanced cardiovascular fitness (Barnett et al., 2008a) and greater perceived sports competence (Barnett et al., 2008b). These factors all contribute to an increased likelihood of long-term participation in sport and exercise. Furthermore, motor skill proficiency is inversely associated with sedentary activity in children (Wrotniak et al., 2006), suggesting that promoting young children's physical activity levels and motor skill proficiency could improve later-life physical activity levels and potentially prevent obesity.

Recent studies have found that between $4 \%-10 \%$ of children aged under five years are not meeting physical activity guidelines that suggest engaging in 180 minutes of physical activity a day (Goldfield et al., 2012; Hnatiuk et al., 2012). There is an assumption that toddlers and young children are naturally active, however, the vast majority of physical activity that young children engage in is low intensity and, therefore, children may not be meeting physical activity requirements (Hnatiuk et al., 2012; Gubbels et al., 2012). Consequently, it may be important for physical activity guidelines, for both parents and practitioners, to specify the required intensity and duration of physical activity to ensure the benefits of improved bone properties, aerobic fitness and motor and cognitive skills are gained. In New Zealand, where there are currently no specific physical activity guidelines for preschool children, it is particularly important to develop appropriate and specific guidelines to support preschool children's physical activity. Furthermore, the links between fundamental movement skills and physical activity are less well understood and so a review in this area is warranted. Although there is limited research in regards to New Zealand preschool children's physical activity and most studies are small scale and qualitative (Stephenson, 1999; Lockie \& Wright, 2002; Oliver \& McLachlan, 2006), research and statistics related to childhood obesity, and the rising obesity rates in New Zealand, indicate that sedentary behavior is a mitigating factor. There is recent evidence from the "Growing up in New Zealand" study that two year olds are spending at least 1.5 hours per day in sedentary screen watching (Morton et al., 2014). Furthermore, children living in socioeconomically deprived areas are more likely to engage in sedentary behaviors, such as watching two or more hours of television each day, and are more likely to be obese (NZ Ministry of Health, 2014).

The aim of this review is to identify key issues related to physical activity and motor skill development in preschool children. The review includes studies that have investigated the following relationships: motor skills, physical activity and cognitive development; young children's motor skills, fundamental movement 
skills and later life fitness and physical activity levels; physical activity and physical literacy interventions; and the influence of the multicultural New Zealand context. Due to the expansive differences that exist between children of various ages, we have adopted the terms set out by the New Zealand Ministry of Education (2009), which categorise young children into three overlapping groups: infants for children aged up to 18 months; toddlers for children aged between one to three years; and young children aged between two and a half years up to school entry, who are also often referred to as preschool children. The term children will be used for those that have reached the age of school entry (five years old). In New Zealand, children tend to enter school on or around their fifth birthday, which is different to many other countries.

\section{Methods}

This exploratory literature review was conducted using the following databases: Medline, SportDiscus, Web of Science, Scopus, Scifinder Scholar and JSTOR. These databases were searched using various combinations of the key words: infants; toddlers; preschool children; young children; motor skill development; physical activity; cognitive development; safety skills; injury rate; attachment; supervision; and social interaction. No restrictions on date of publication were used. In addition to the articles found using database searches, all pertinent articles from the bibliographies of the articles were also reviewed. Furthermore, government websites such as the Ministry of Education, Ministry of Health and Sport New Zealand were examined for pertinent publications and reports.

\section{Motor Development}

Fine motor development is the development and control of small movement skills, such as reaching and grasping, while gross motor development refers to control over larger movement skills that tend to be less refined, such as crawling, standing and walking (Berk, 2005). Early views of child development were based on the achievement of developmental milestones, largely centred on the research of Gesell (1925). More recently, Mercer (1998) has suggested that there are two major categories of development: maturation and learning. Maturation describes the developmental changes that occur due to the instructions built into DNA (Harris \& Liebert, 1992), which include changes attributed to growth. Learning describes the permanent changes that occur in thinking and behavior when children play an active role in their own development, when both perceptual and social incentives promote the progression of skills (Bruner, 1973). Child development is increasingly recognised as a dynamic system, strongly influenced by a variety of factors, including interaction with peers, families, societies and cultures (Thelen et al., 1991; Greenfield \& Cocking, 2014). The dynamic perspective recognises that even small differences in experience or environment at a young age can result in dramatic differences in later behavior (Smith \& Thelen, 2003).

As dynamic perspectives of development suggest, all children develop at different rates and, while there is a typical order of development due to maturation 
(Brierley, 1993), patterns or milestones may vary in children from different cultures, ethnicities and communities because different opportunities in individual contexts also lead to the development of different physical skills or proficiencies (Adolph \& Berger, 2005). One implication of this is that in the early years of life, developmental age is often deemed to be a more relevant assessment measure than chronological age (Foster \& Hartigan, 2006), especially for children born pre-term or with very low or extremely low birth weight (VLBW and ELBW, respectively). Therefore, some researchers report findings in terms of developmental age as opposed to chronological age.

\section{Typical Development}

Although the sequence of motor development is fairly uniform, children develop at different rates and in different ways, influenced by factors such as environment, experience and culture, as well as genetics and growth (Berk, 2005; Thelen et al., 1991; Greenfield \& Cocking, 2014). Both fine and gross motor development are influenced by cephalocaudal development and proximodistal development in the typically developing child (Berk, 2005; Adolph \& Berger, 2005). Through these cephalocaudal and proximodistal trends, upper body control is achieved first, followed by arm control, and then finger control (Berk, 2005). For toddlers ( 1 - 3 years-old) development is rapid, with the most obvious changes occurring in language and motor skills (Colson \& Dworkin, 1997). Toddlers' motor development is typically characterised by the commencement of walking and other gross motor skills such as running, jumping and hopping (Cardon et al., 2011). Fine motor skills, such as writing, drawing or manipulating blocks, also develop and progress during the toddler period (Cardon et al., 2011).

As children grow, their bodies become less top heavy and more streamlined, their perceptual and cognitive capacities grow, and building on existing motor skills, they learn more complex movement patterns (Berk, 2005). Children's more complex motor skills are sometimes referred to as fundamental movement skills, and further categorised as locomotor skills and object control skills. Locomotor skills involve body movement and include skills such as running, skipping and jumping (Barnett et al., 2008a). Object control skills are those that involve manipulation of an object, for example throwing, catching and kicking (Barnett et al., 2008a). Locomotor and object control skills are considered to be fundamental for future movement and engagement in later-life physical activity (Foulkes et al., 2013). Numerous studies have found relationships between motor development, fundamental movement proficiency and physical activity behaviors (Barnett et al., 2008a; Barnett et al., 2009; Barnett et al., 2008b; Okely et al., 2001; Piek et al., 2006; Ridgway et al., 2009).

\section{Associations between Physical Literacy and Physical Activity}

An in-depth analysis of the potential correlates with children's physical activity was completed by Sallis et al. (2000). They found that a variety of variables, in- 
cluding gender, parental overweight status, physical activity preferences, intention to be active, previous physical activity and time spent outdoors, were significantly associated with children's physical activity. Physical literacy has been defined as "the motivation, confidence, physical competence, knowledge and understanding to value and take responsibility for engagement in physical activities for life" (Whitehead, 2010: pp. 11-12). The abundance of these associated variables suggests that further research needs to incorporate a wide variety of intervention methods to ensure young children have the best chance of improvement in physical literacy and physical activity measures.

Research also supports the general hypothesis that specific physical activities are related to specific motor control skills. Butcher and Eaton (1989) found that daily indoor free play of 5-year-old children, in early childhood centres, was positively related to running speed. On the other hand, they found that children who participated in low intensity, fine motor activities were more likely to have good visual motor control and balance.

Ridgway and colleagues (2009) observed motor development in 9009 individuals born in 1966, and related the age of walking with support or age of standing unaided with school physical education (PE) grade and self-reported sports participation when the children were 14 years old. This comprehensive, longitudinal study showed that earlier motor development in infancy is associated with a higher school PE grade. In addition, age of walking was positively associated with the number of sports played and with the frequency of sports participation. These findings were independent of potential contributing factors such as gestational age and birth weight and body mass index at follow up. Ridgway and colleagues' (2009) epidemiological study supports the findings of Barnett and colleagues (Barnett et al., 2008a; Barnett et al., 2008b; Barnett et al., 2009) that improving motor skill proficiency at a young age may be a key strategy for improving later physical activity levels and fitness.

\section{Physical Activity Guidelines for Infants, Toddlers and Young Children}

There are no established physical activity guidelines for children aged birth to five years in New Zealand, however it is suggested that children under five should be encouraged to "move every day" (Ministry of Health, 2012) and there are a set of physical activity resource documents available from Sport NZ. As other countries, such as Australia (Australian Government Department of Health and Aging, n.d.), the United Kingdom (UK; Physical Activity and Health alliance, 2013) and United States of America (USA; Cliff et al., 2009), utilise specific physical activity recommendations for toddlers and young children, the need for appropriate and specific guidelines for New Zealand's infants and toddlers is highlighted. Table 1 illustrates the similarities and differences between the recommendations of the aforementioned countries.

A limitation in these guidelines is that those from the USA and UK lack specific ages and instead simply refer to infants, toddlers, preschoolers and children. 
Table 1. Physical activity guidelines for infants and toddlers in selected western countries.

\begin{tabular}{|c|c|c|}
\hline Australia & United Kingdom & United States of America \\
\hline $\begin{array}{c}\text { For infants (0 - } 1 \text { year) } \\
\text { physical activity, particularly } \\
\text { supervised floor play in safe } \\
\text { environments, should be } \\
\text { encouraged from birth. }\end{array}$ & $\begin{array}{l}\text { Infants should be encouraged } \\
\text { to be physically active daily, } \\
\text { particularly through } \\
\text { floor-based play in } \\
\text { safe environments. }\end{array}$ & $\begin{array}{l}\text { Infants should interact with } \\
\text { parents and/or caregivers in } \\
\text { daily physical activities } \\
\text { dedicated to promoting } \\
\text { exploration. }\end{array}$ \\
\hline $\begin{array}{l}\text { Toddlers ( } 1 \text { - } 3 \text { years) and } \\
\text { preschoolers ( } 3 \text { - } 5 \text { years }) \\
\text { should be physically active for } \\
\text { at least } 3 \text { hours every day, } \\
\text { spread throughout the day. }\end{array}$ & $\begin{array}{l}\text { Children capable of walking } \\
\text { unaided should be physically } \\
\text { active for at least } \\
3 \text { hours daily. }\end{array}$ & $\begin{array}{c}\text { Toddlers should accumulate } \\
\text { at least } 30 \text { minutes of } \\
\text { structured and at least } 60 \\
\text { minutes of unstructured } \\
\text { physical activity every day. }\end{array}$ \\
\hline $\begin{array}{l}\text { Children younger than } 2 \text { years } \\
\text { should not spend any time } \\
\text { watching television or using } \\
\text { other electronic media } \\
\text { (DVDs, computer etc.). For } \\
\text { children between } 2 \text { - } 5 \text { years } \\
\text { these activities should be } \\
\text { limited to less than one hour } \\
\text { per day. }\end{array}$ & $\begin{array}{l}\text { Infants and children should } \\
\text { be discouraged from being } \\
\text { sedentary. No sedentary } \\
\text { behaviour should last for } \\
\text { more than } 1 \text { hour } \\
\text { (except sleep). }\end{array}$ & $\begin{array}{c}\text { Pre-schoolers should } \\
\text { accumulate at least } 60 \\
\text { minutes of structured and at } \\
\text { least } 60 \text { minutes, and up to } \\
\text { several hours, of unstructured } \\
\text { physical activity every day, } \\
\text { and should not be sedentary } \\
\text { for more than } 60 \text { minutes } \\
\text { (unless asleep). }\end{array}$ \\
\hline $\begin{array}{l}\text { Source: Australian } \\
\text { Government Department of } \\
\text { Health and Aging (no date) }\end{array}$ & $\begin{array}{l}\text { Source: Physical Activity and } \\
\text { Health Alliance (no date) }\end{array}$ & $\begin{array}{c}\text { Source: National Association } \\
\text { for Sport and Physical } \\
\text { Education (NASPE) Active } \\
\text { Start Guidelines (as cited in } \\
\text { Cliff et al., 2009) }\end{array}$ \\
\hline
\end{tabular}

Guidelines from the UK utilise specific milestones (such as walking unaided) to further define children, however, it is unclear up to what age this group incorporates.

Studies have shown that children are often not meeting physical activity guidelines, with Goldfield et al. (2012) reporting that only $9 \%$ of boys and $4 \%$ of girls are meeting the Canadian Physical Activity Guidelines. Conversely, Hnatiuk et al. (2012) reported $90.5 \%$ of toddlers met current Australian physical activity guidelines for children aged birth to five years (Australian Government Department of Health and Aging, n.d.). While Canada and Australia have similar guidelines in that both suggest young children should engage in 180 minutes of physical activity a day, the Canadian guidelines further define physical activity in terms of intensity level and suggest that children should accrue 60 minutes of moderate-to-vigorous physical activity a day, and this specifically is not being met. As there is an assumption that toddlers and young children are naturally active, it may be important for physical activity guidelines to specify the required intensity and duration of physical activity to ensure the benefits of improved bone properties, aerobic fitness and motor skills are gained. However, there is limited and often contradictory literature surrounding the amount of physical activity young children and toddlers should be doing (Timmons et al., 2007). It 
is therefore important that further research, including both observational and intervention studies, is undertaken to ensure specific and achievable guidelines are developed, especially in the New Zealand context where, to date, there are no specific physical activity guidelines for children under five years old.

\section{Intervention Studies}

Early intervention is "the delivery of coordinated and comprehensive specialised services for children with developmental delays or those at-risk of developing disabilities or delays and their families from birth or point of identification until they enter the formal education system" (McLachlan et al., 2013). The purpose of such programmes is based on a hypothesis that children can reach their predetermined brain development potential with early support, but may also enhance this potential (Holt \& Mikati, 2011). Most intervention studies concentrate on children with, or at risk of, neurological or motor deficiencies (Angulo-Barroso et al., 2008; Valvano \& Rapport, 2006) or as prevention programmes for children at risk of obesity (Bluford et al., 2007). The focus of preventing obesity by early intervention is the focus of this review; issues of special education are important, but beyond the scope of this review.

The effects of physical activity on young children's motor skills and physical activity levels have been examined in a few intervention studies (Alpert et al., 1990; Matvienko \& Ahrabi-Fard, 2010; Reilly et al., 2006). In particular, Alpert et al. (1990) found that daily aerobic exercises for 30 minutes over eight weeks improved agility (which was assessed with a specifically designed agility test consisting of 10 motor agility items) and cardiovascular fitness in 24 three to fiveyear-old children when compared to a control group that undertook free-play in a playground. However, both the control and intervention groups showed an increase in physical activity levels, which were assessed by observing the children in the playground for three 10-minute periods before and following the intervention period. The increase in both groups could be explained by the assessment method, which did not specifically measure the intensity, rigor, or endurance of physically active play. Another explanation is that, because both groups were observed playing together, an increase in one group's physically active behavior elicited more activity from the other group (Alpert et al., 1990). Likewise, a Scottish study (Reilly et al., 2006) found that a physical activity programme (three 30-minute sessions a week over 6 months), plus home-based health education aimed at increasing physical activity through play, related to a significant improvement in 4 year-old children's ( $\mathrm{n}=545$ at baseline) gross motor skills, tested using the Movement Assessment Battery (Fisher et al., 2005) six months and then 12 months after the intervention. Both intervention studies (Alpert et al., 1990; Reilly et al., 2006) highlight the potential of physical activity interventions to improve children's fundamental movement skills, an improvement which is linked to an increase in later-life physical activity levels and participation in sports.

Matvienko and Ahrabi-Fard (2010) examined the short and longer-term ef- 
fects of a four-week physical activity programme on jump rope, throwing, and shuttle runs in kindergarten and first-grade (5 - 7 year-old) children in Iowa, USA. The findings from this randomised control trial suggest that even with as little as four weeks of directed physical activity, improvements in motor skills can occur in school-aged children. A significant improvement in shuttle runs observed at the follow-up test is contradictory to other studies that show that cardiovascular fitness is often lost over breaks (Carrel et al., 2005). Matvienko and Ahrabi-Fard (2010) suggest that this difference may be due to the different emphasis of the intervention, which had a focus on fundamental movement skill acquisition as opposed to active lifestyle or cardiovascular fitness. Therefore, further research examining the effects of different intervention strategies may be required to determine the most effective methods of promoting physical activity and enhancing motor skill development. In addition, further research with younger children is implicated.

A randomised, controlled design was used by New Zealand researcher, Pigou (2013), as part of an unpublished Master's thesis. This research investigated the effects of a child-centered physical literacy intervention, Jumping Beans, on toddlers' $(n=90)$ overall development, safety skills, balance and parent supervision. After nine weeks of one hour physical literacy sessions, toddlers' safety skills and abilities to complete agility tasks improved, although there was no difference in overall development measures or improvement in balance. Pigou's study, the first randomised, controlled trial to examine the effects of a physical literacy intervention for New Zealand toddlers, provides a foundation for further research.

Several studies have also examined the effects of physical activity intervention programmes on measures of fatness in young children (Fitzgibbon et al., 2005; Mo-suwan et al., 1998; Moore et al., 1995). A 29-week intervention incorporating a 15-minute walk and a 20-minute aerobic dance class three times per week was found to reduce body mass index (BMI) gain in girls (4 - 5 years old) only (Mo-suwan et al., 1998). Similarly, a longitudinal study examining the effect of physical activity on body fatness in children aged 3 - 5 years old found that inactive children of the same age were 3.8 times more likely than active children to have an increase in body fatness, as determined by the slope of triceps brachii skinfolds (Moore et al., 1995). Although there was no significant gender difference, active girls still gained $1.0 \mathrm{~mm}$ in their triceps brachii skinfold while active boys lost $0.75 \mathrm{~mm}$ on average. This variance between genders suggests that it is important to control for gender when examining the effect of an intervention on fatness, even in young children.

Another longitudinal study, with a randomised, controlled design, found that children aged up to four years old who received a weight-control intervention (as opposed to a general health intervention) had reduced BMI increases at one and two years following the intervention period (Fitzgibbon et al., 2005). The weight-control intervention (Hip-Hop to Health Jr.) included a 20-minute lesson on healthy eating or exercise and 20 minutes of physical activity, three times a week for 14 weeks, and was not specifically targeted at overweight children but 
was inclusive of all children at the schools included in the study. The sample was predominately African-American as this group was identified as particularly at risk of becoming overweight or obese (Hedley et al., 2004).

In sum, further research to identify successful, sustainable interventions for the promotion of physical literacy and physical activity in young children is important. In particular, further information is needed regarding the effectiveness of various intervention programmes, given variables such as the participants' age, health status, ethnicity and gender and also factors such as context, duration of intervention and the assessment methods used. In this context, New Zealand research is particularly limited.

\section{Associations between Motor Skills and Cognitive Development}

Cognitive development includes a wide range of abilities and skills that are involved with learning, thinking and intelligence. The areas of cognition include information processing, remembering, planning, reasoning, problem solving, categorising and creating (Berk, 2013). Cognitive development is interrelated with the social, cultural, emotional and physical environments in which people live and intricately interrelated with other domains of learning, including movement and motor development (Smith, 2013).

The proposed relationship between motor development and cognitive development is not a new one, with early studies by Piaget (1953) suggesting that activity and sensorimotor experiences influence cognitive ability. Since then, several studies have examined the association between motor skill development in infants, toddlers and young children and cognitive ability in later life (Burns et al., 2004; Bushnell \& Boudreau, 1993; Williams \& Holley, 2013) and neuroscience techniques have provided greater insights in regards to brain development (Casey et al., 2005; Diamond, 2000). Brain imaging shows that brain regions associated with primitive motor and sensory functioning mature first, followed by brain regions associated with cognition and action (Casey et al., 2005) supporting the argument that basic sensory-motor skills form the foundation for higher-order cognitive abilities (Diamond, 2000). However, the relationship between movement and cognition is more complex and reciprocal than this explanation suggests. Support for the inter-relationship between motor and cognitive development comes from a summary of neuroimaging studies, which found that mutual brain structures are used for both motor and cognitive functioning and suggest that when deficits in motor ability are observed, so too are reductions in cognitive ability and vice versa (Diamond, 2000; Wassenberg et al., 2005).

Piek and colleagues (2008) showed that gross motor skill in children aged four months to four years was a significant predictor of cognitive performance when children reached school age (6 - 11.5 years), while fine motor skill was not. This finding can be explained by the proposition that achievement of certain milestones creates a foundation to support the progression of more challenging skills (Casey et al., 2005; Diamond, 2000) and the suggestion that cognitive develop- 
ment is reciprocally entwined with movement experiences (Diamond, 2000; Wassenberg et al., 2005). One implication is that gross motor skill acquisition in early childhood may be a better predictor of cognitive performance at school than fine motor skill, suggesting the need for teachers to encourage development of gross motor skills in early childhood programmes.

Gestational age at birth has been found to be a significant determinant of later motor and cognitive ability, with children born before 29 weeks or below $1000 \mathrm{~g}$ at the greatest risk of developmental deficiencies in later life (Piek et al., 2008). For this reason, much of the literature regarding the associations between motor skill (both fine and gross) and cognitive ability has concentrated on pre-term or VLBW and ELBW children (Burns et al., 2004). This suggests that while assessment of gross motor skill in physical activity intervention studies may provide little information regarding the effectiveness of the intervention, this type of assessment can provide valuable information regarding future cognitive ability. Furthermore, future research on motor skill and cognitive development in infancy potentially needs to control for gestational age and/or birth weight.

Research supports a link between early movement and later cognitive learning. Infants, toddlers and young children who have increased opportunities to move and to improve motor skills may be more likely to develop greater cognitive and academic skills, than those who experience limited opportunities for physical activity.

\section{The New Zealand Context}

Most New Zealand research regarding young children's physical activity relates to addressing obesity issues. In 2014, about $31 \%$ of New Zealand children between 2 - 14 years old were classified as either overweight (21\%) or obese (10\%) (Ministry of Health, 2014). Contributing factors include poverty, housing conditions, food security, and the cost of healthy food. Māori children and children from the Pacific Islands are more likely to be obese; $17 \%$ of Māori children and $23 \%$ of Pacific Island children were identified as obese in 2012 (Ministry of Health, 2014). Children living in socioeconomically deprived areas (65\% of Māori and $78 \%$ of Pacific Island people live in socioeconomically deprived neighbourhoods) are more likely to be obese and tend to engage in sedentary behaviors more often (Ministry of Health, 2014).

The Ministry of Health Clinical Trials Research Unit (Ministry of Health, 2009) recommends interventions that gradually increase an (obese) child's daily physical activity until the child is able to regularly engage in moderate to vigorous intensity physical activity for at least 60 minutes per day. One such intervention is the Green Prescription Active Families (GRxAF) programme, which is designed to increase physical activity in 5 - 18 year-old children and their families. GRxAF offers positive ways to address some of the issues related to sedentary behavior and obesity (Wood \& Johnson, 2013).

A more recent intervention, the New Zealand government's Childhood Obesity Plan (Ministry of Health, 2015) is designed to offer targeted interventions for 
those who are obese, increase support for people at risk of becoming obese and to offer a broad approach to support healthier lifestyles for all New Zealanders. The plan supports better collaboration between existing initiatives across government agencies, the private sector, communities, schools, families and whānau (family) (Ministry of Health, 2015). Physical activity is one focus of the Childhood Obesity Plan, which also targets diet and environmental factors. Physical activity initiatives for children over the age of five include a number of sports and education programmes and a teacher training initiative, mostly to be delivered through schools (Ministry of Health, 2015). There is less focus on preschool children, with physical activity initiatives in the form of family focused initiatives and a plan to introduce physical activity guidelines for preschool children. Presently, in New Zealand, access to services aimed at encouraging physical activity are limited, particularly for preschool children, as is research that evaluates the effectiveness of such intervention programmes. Research needs to focus on preschool children and to examine the impact of early intervention.

Anderson et al. (2015) investigated the effectiveness of various interventions offered to 290 obese and overweight children and adolescents ( 3 - 16 years) in New Zealand. Interventions included: medical follow-up by a paediatrician at regular intervals; medical follow-up by a paediatrician and dietitian input at regular intervals; medical follow-up, dietitian and GRxAF input; and a multidisciplinary intervention programme. Irrespective of the type of intervention provided, there were consistent reductions in BMI SDS (body mass index standard deviation score) over time. The extent of BMI SDS reduction was significantly affected by the participant's age at entry, suggesting that younger children may benefit more from interventions than their older peers. Interventions to help obese and overweight children lose weight can make a positive difference; however, further research is needed to thoroughly evaluate the effectiveness of intervention programmes in the New Zealand context (Anderson et al., 2015). Research that investigates physical activity interventions for general populations of New Zealand preschoolers, rather than exclusively focusing on children who are overweight, is scarce.

\section{Physical Activity in Early Education Settings}

In New Zealand, the average number of hours preschool children spend in early education settings has increased from 16.1 hours per week in 2004 to 21.7 hours per week in 2013 (Ministry of Education, 2014). The international and New Zealand literature suggests that, during their time in early education settings, infants, toddlers and young children may not engage in the physical activity they need (Sugiyama et al., 2012; Oliver et al., 2007). Numerous factors, including opportunities to be active, types of play equipment, environment and space, the regulatory environment, and teachers' perceptions and knowledge of physical activity, contribute to young children's levels of physical activity in early education settings (Coleman \& Dyment, 2013; Hesketh et al., 2015). 
In New Zealand early education centres, the regulatory environment represents minimum standards that are interpreted by various centres via philosophy, culture and community (McLachlan, 2015). Implementation of physical activity opportunities tends to rely on teacher knowledge within a diversity of services and in a context lacking in research-based information regarding preschool children's physical activity (McLachlan, 2015). Oliver et al. (2007) identified that, in New Zealand early education centres, prioritisation of academic learning over physical activity, a general culture shift towards inactivity and sedentary pursuits, centre policies, limited initial teacher education and in service professional learning, confidence and support, and scheduled or limited time outdoors are barriers to young children's physical activity. Likewise, Australian research found that, although most teachers recognise the importance of young children's physical activity, numerous factors limit physical activity in early education settings, including lack of specialised teacher training and knowledge, policies and procedures, safety concerns, and teacher-child ratios (Coleman \& Dyment, 2013).

In an American study, Hesketh et al. (2015) examined 203 teachers' beliefs and perceptions about infants' and toddlers' physical activity. Most of the teachers believed that they played an important role in promoting toddlers' physical activity, however, most teachers lacked knowledge about young children's physical activity requirements and most believed that toddlers required just a short amount of daily physical activity (below the recommended guidelines). Both these studies draw attention to the need for specialised teacher education in the domain of young children's physical activity. Hesketh et al. (2015) highlight the possibilities of early education settings as plausible and potentially successful settings for physical activity interventions that offer physical activity programmes for young children and simultaneously increase teachers' physical activity knowledge.

\section{Conclusion}

There is a wealth of studies on the development of children's motor skills and physical activity; studies which show correlations between, on the one hand, motor skills and physical activity in the early years and, on the other hand, cognitive abilities, physical activity, bodymass index and motor skills in later years. Nonetheless, there are large gaps in the research, particularly where studies have implied an abundance of associated variables, for example, with gender-specific outcomes, that may not have been accounted for or where there are variations in findings. In particular, there is a dearth of research in the multicultural New Zealand-specific conditions, specifically for preschool children. The available literature suggests planning for physical activity needs to start from an early age and policies and guidelines need to be in place for the benefits of parents and educators; at present only a handful of countries have guidelines for physical activity in pre-school children. While it seems that physical literacy interventions can promote motor skill competence, physical activity levels and related positive 
health outcomes, more research is needed to thoroughly evaluate interventions that work for preschool children.

\section{References}

Adolph, K. E., \& Berger, S. E. (2005). Physical and Motor Development. In M. H. Bornstein, \& M. E. Lamb (Eds.), Developmental Science: An Advanced Textbook (5th ed., pp. 223-281). New York: Psychology Press/Taylor \& Francis.

Alpert, B., Field, T. M., Goldstein, S., \& Perry, S. (1990). Aerobics Enhances Cardiovascular Fitness and Agility in Preschoolers. Health Psychology, 9, 48-56.

https://doi.org/10.1037/0278-6133.9.1.48

Anderson, Y. C., Cave, T. L., Cunningham, V. J., Perieira, N. M., Woolerton, D. M., Grant, C., \& Hofman, P. L. (2015). Effectiveness of Current Interventions in Obese New Zealand Children and Adolescents. New Zealand Medical Journal, 128.

Angulo-Barroso, R., Burghardt, A. R., Lloyd, M., \& Ulrich, D. A. (2008). Physical Activity in Infants with Down Syndrome Receiving a Treadmill Intervention. Infant Behavior Development, 31, 255-269. https://doi.org/10.1016/j.infbeh.2007.10.003

Australian Government Department of Health and Aging (No Date). Physical Activity Recommendations for Children 0-5 Years.

http://www.health.gov.au/internet/main/publishing.nsf/content/health-pubhlth-strateg -phys-act-guidelines\#npa05

Barnett, L. M., Morgan, P. J., van Beurden, E., \& Beard, J. R. (2008b). Perceived Sports Competence Mediates the Relationship between Childhood Motor Skill Proficiency and Adolescent Physical Activity and Fitness: A Longitudinal Assessment. International Journal of Behavioural Nutrition and Physical Activity, 5, 40-52. https://doi.org/10.1186/1479-5868-5-40

Barnett, L. M., van Beurden, E., Morgan, P. J., Brooks, L. O., \& Beard, J. R. (2008a). Does Childhood Motor Skill Proficiency Predict Adolescent Fitness? Medicine and Science in Sports and Exercise, 40, 2137-2144. https://doi.org/10.1249/MSS.0b013e31818160d3

Barnett, L. M., van Beurden, E., Morgan, P. J., Brooks, L. O., \& Beard, J. R. (2009). Childhood Motor Skill Proficiency as a Predictor of Adolescent Physical Activity. Journal of Adolescent Health, 44, 252-259. https://doi.org/10.1016/j.jadohealth.2008.07.004

Berk, L. E. (2005). Infants, Children and Adolescents (5 ${ }^{\text {th }}$ ed.). Boston, MA: Pearson.

Berk, L. E. (2013). Child Development (9 $9^{\text {th }}$ ed.). Boston, MA: Pearson.

Bluford, D. A. A., Sherry, B., \& Scanlon, K. S. (2007). Interventions to Prevent or Treat Obesity in Preschool Children: A Review of Evaluated Programs. Obesity, 15, 1356 1372. https://doi.org/10.1038/oby.2007.163

Brierley, J. (1993). Growth in Children. London: Cassell Education Limited.

Bruner, J. S. (1973). Organization of Early Skilled Action. Child Development, 44, 1-11. https://doi.org/10.2307/1127671

Burns, Y., O’Callaghan, M., McDonell, B., \& Rogers, Y. (2004). Movement and Motor Development in ELBW Infants at 1 Year Is Related to Cognitive and Motor Abilities at 4 Years. Early Human Development, 80, 19-29. https://doi.org/10.1016/j.earlhumdev.2004.05.003

Bushnell, E. W., \& Boudreau, J. P. (1993). Motor Development and the Mind: The Potential Role of Motor Abilities as a Determinant of Aspects of Perceptual Development. Child Development, 64, 1005-1021. https://doi.org/10.2307/1131323

Butcher, J. E., \& Eaton, W. O. (1989). Gross and Fine Motor Proficiency in Preschoolers: Relationships with Free Play Behaviour and Activity Level. Journal of Human Move- 
ment Studies, 16, 27-36.

Cardon, G., Van Cauwenberghe, E., \& De Bourdeaudhuij, I. (2011).What Do We Know about Physical Activity in Infants and Toddlers: A Review of the Literature and Future Research Directions. Science and Sports, 26, 127-130.

https://doi.org/10.1016/j.scispo.2011.01.005

Carrel, A. L., Clark, R. R., Peterson, S. E., Nemeth, B. A., Sullivan, J., \& Allen, D. B. (2005). Improvement of Fitness, Body Composition and Insulin Sensitivity in Overweight Children in a School-Based Exercise Program: A Randomized, Controlled Study. Archives of Pediatrics and Adolescent Medicine, 159, 963-968. https://doi.org/10.1001/archpedi.159.10.963

Casey, B. J., Tottenham, N., Liston, C., \& Durston, S. (2005). Imaging the Developing Brain: What Have We Learned about Cognitive Development? Trends in Cognitive Sciences, 9, 104-110. https://doi.org/10.1016/j.tics.2005.01.011

Cliff, D. P., Reilly, J. J., \& Okely, A. D. (2009). Methodological Considerations in Using Accelerometers to Assess Habitual Physical Activity in Children Aged 0-5 Years. Journal of Science and Medicine in Sport, 12, 557-567. https://doi.org/10.1016/j.jsams.2008.10.008

Coleman, B., \& Dyment, J. E. (2013). Factors That Limit and Enable Preschool-Aged Children's Physical Activity on Child Care Centre Playgrounds. Journal of Early Childhood Research, 11, 203-221. https://doi.org/10.1177/1476718X12456250

Colson, E. R., \& Dworkin, P. H. (1997). Toddler Development. Pediatrics Review, 18, 255-259. https://doi.org/10.1542/pir.18-8-255

Diamond, A. (2000). Close Interrelation of Motor Development and Cognitive Development and of the Cerebellum and Prefrontal Cortex. Child Development, 71, 44-56. https://doi.org/10.1111/1467-8624.00117

Fisher, A., Reilly, J. J., Kelly, L. A., Montgomery, C., Williamson, A., Paton, J. Y., \& Grant, S. (2005). Fundamental Movement Skills and Habitual Physical Activity in Young Children. Medicine and Science in Sports and Exercise, 37, 684-688. https://doi.org/10.1249/01.MSS.0000159138.48107.7D

Fitzgibbon, M. L., Stolley, M. R., Schiffer, L., Van Horn, L., Kaufer Christoffel, K., \& Dyer, A. (2005). Two-Year Follow-Up Results for Hip-Hop to Health Jr.: A Randomized Controlled Trial for Overweight Prevention in Preschool Minority Children. Journal of Pediatrics, 146, 618-625. https://doi.org/10.1016/j.jpeds.2004.12.019

Foster, S., \& Hartigan, J. (2006). Move Baby Move. Auckland: Random House New Zealand.

Foulkes, J. D., Knowles, Z., Fairclough, S. J., Stratton, G., O’Dwyer, M., Ridgers, N. D., \& Foweather, L. (2013). Fundamental Movement Skills of Preschool Children in Northwest England. Perceptual and Motor Skills, 121, 260-283. https://doi.org/10.2466/10.25.PMS.121c14x0

Gesell, A. (1925). The Mental Growth of the Preschool Child. New York, NY: Macmillan.

Goldfield, G. S., Harvey, A., Grattan, K., \& Adamo, K. B. (2012). Physical Activity Promotion in the Preschool Years: A Critical Period to Intervene. International Journal of Environmental Research and Public Health, 9, 1326-1342. https://doi.org/10.3390/ijerph9041326

Greenfield, P. M., \& Cocking, R. R. (2014). Cross Cultural Roots of Minority Child Development. Hove: Psychology Press.

Gubbels, J. S., Van Kann, D. H. H., \& Jansen, M. W. J. (2012). Play Equipment, Physical Activity Opportunities, and Children's Activity Levels at Childcare. Journal of Environmental and Public Health, 2012, Article ID: 326520. 
Gunner, K. B., Atkinson, P. M., Nichols, J., \& Eissa, M. A. (2005). Health Promotion Strategies to Encourage Physical Activity in Infants, Toddlers, and Preschoolers. Journal of Pediatric Health Care, 19, 253-258. https://doi.org/10.1016/j.pedhc.2005.05.002

Harris, J. R., \& Liebert, R. M. (1992). Infant and Child: Development from Birth through Middle Childhood. Englewood Cliffs, NJ: Prentice-Hall Inc.

Hedley, A. A., Ogden, C. L., Johnson, C. L., Carroll, M. D., Curtin, L. R., \& Flegal, K. M. (2004). Prevalence of Overweight and Obesity among US Children, Adolescents, and Adults, 1999-2002. Journal of the American Medical Association, 291, 2847-2850. https://doi.org/10.1001/jama.291.23.2847

Hesketh, K. R., van Sluijs, E. M., Blaine, R. E., Taveras, E. M., Gillman, M. W., \& Benjamin Neelon, S. E. (2015). Assessing Care Providers' Perceptions and Beliefs about Physical Activity in Infants and Toddlers: Baseline Findings from the Baby NAP SACC Study. BMC Public Health, 15, 100. https://doi.org/10.1186/s12889-015-1477-z

Hnatiuk, J., Ridgers, N. D., Salmon, J., Campbell, K., McCallum, Z., \& Hesketh, K. (2012). Physical Activity Levels and Patterns of 19-Month-Old Children. Medicine and Science in Sports and Exercise, 44, 1715-1720. https://doi.org/10.1249/MSS.0b013e31825825c4

Holt, R. L., \& Mikati, M. A. (2011). Care for Child Development: Basic Science Rationale and Effects of Interventions. Pediatric Neurology, 44, 239-253.

https://doi.org/10.1016/j.pediatrneurol.2010.11.009

Lockie, C., \& Wright, J. (2002). The Golden Kiwi Childhood-Is It a Lottery? New Zealand Research in Early Childhood Education, 5, 157-167.

Matvienko, O., \& Ahrabi-Fard, I. (2010). The Effects of a 4-Week After-School Program on Motor Skills and Fitness of Kindergarten and First-Grade Students. American journal of Health Promotion, 24, 299-303. https://doi.org/10.4278/ajhp.08050146

McLachlan, C. (2015). Children's Wellbeing. Early Education, 57, 19-23.

McLachlan, C., Fleer, M., \& Edwards, S. (2013). Early Childhood Curriculum: Planning, Assessment and Implementation. Melbourne: Cambridge University Press. https://doi.org/10.1017/CBO9781107282193

Mercer, J. (1998). Infant Development: A Multidisciplinary Introduction. Pacific Grove, CA: Brooks/Cole Publishing Company.

Ministry of Education (2009). Early Childhood Care and Education for Infants, Toddlers, and Young Children.

http://www.educate.ece.govt.nz/learning/curriculumAndLearning/TeWhariki/PartA/E arlyChildhoodCareAndEducation.aspx

Ministry of Education (2014). Annual ECE Census Summary Report. https://www.educationcounts.govt.nz/statistics/early-childhood-education

Ministry of Health (2012). How Much Activity Is Recommended? http://www.health.govt.nz/yourhealth-topics/physical-activity/how-much-activity-reco mmended

Ministry of Health (2014). Annual Update of Key Results 2013/14: New Zealand Health Survey. Wellington: Ministry of Health.

http://www.health.govt.nz/system/files/documents/publications/annual-update-key-res ults-nzhs-2013-14-dec14-v2.pdf

Ministry of Health (2015). Childhood Obesity Plan.

http://www.health.govt.nz/our-work/diseases-and-conditions/obesity/childhood-obesit y-plan

Ministry of Health Clinical Trials Research Unit (2009). Clinical Guidelines for Weight Management in New Zealand Children and Young People. Wellington: Ministry of 
Health.

https://www.health.govt.nz/system/files/documents/publications/weight-managementchildren-guidelines $0 . p d f$

Moore, L. L., Nguyen, U. D. T., Rothman, K. J., Cupples, L. A., \& Ellison, R. C. (1995). Preschool Physical Activity Level and Change in Body Fatness in Young Children: The Framingham Children's Study. American Journal of Epidemiology, 142, 982-988.

Mo-Suwan, L., Pongprapai, S., Junjana, C., \& Puetpaiboon, A. (1998). Effects of a Controlled Trial of a School-Based Exercise Program on the Obesity Indexes of Preschool Children. American Journal of Clinical Nutrition, 68, 1006-1011.

Okely, A. D., Booth, M. L., \& Patterson, J. W. (2001). Relationship of Physical Activity to Fundamental Movement Skills among Adolescents. Medicine and Science in Sports and Exercise, 33, 1899-1904. https://doi.org/10.1097/00005768-200111000-00015

Oliver, M., \& McLachlan, C. (2006). Physical Activity: An Overview of Policy and Practice in Early Childhood Education and Care. Early Education, 40, 15-19.

Oliver, M., Schofield, G. M., Kolt, G. S., \& McLachlan, C. (2007). Physical Activity in Early Childhood: Current State of Knowledge. New Zealand Research in Early Childhood Education, 10, 47-68.

Physical Activity and Health Alliance. Physical Activity Recommendations for Birth-18 Years in the UK.

http://www.paha.org.uk/Resource/physical-activity-recommendations-for-birth-18-yea rs-in-the-uk

Piaget, J. (1953). The Origin of the Intelligence in the Child. London: Routledge.

Piek, J. P., Baynam, G. B., \& Barrett, N. C. (2006). The Relationship between Fine and Gross Motor Ability, Self-Perceptions and Self-Worth in Children and Adolescents. Human Movement Science, 25, 65-75. https://doi.org/10.1016/j.humov.2005.10.011

Piek, J. P., Dawson, L., Smith, L. M., \& Gasson, N. (2008). The Role of Early Fine and Gross Motor Development on Later Motor and Cognitive Ability. Human Movement Science, 27, 668-681. https://doi.org/10.1016/j.humov.2007.11.002

Reilly, J. J., Kelly, L., Montgomery, C., Williamson, A., Fisher, A., McColl, J. H., \& Grant, S. (2006). Physical Activity to Prevent Obesity in Young Children: Cluster Randomized Controlled Trial. British Medical Journal, 333, 1041. https://doi.org/10.1136/bmj.38979.623773.55

Ridgway, C. L., Ong, K. K., Tammelin, T. H., Sharp, S., Ekelund, U., \& Jarvelin, M. R. (2009). Infant Motor Development Predicts Sports Participation at Age 14 Years: Northern Finland Birth Cohort of 1966. PLoS ONE, 4, e6837.

Robinson, L. E., Stodden, D. F., Barnett, L. M., Lopes, V. P., Logan, S. W., Rodrigues, L. P., \& D'Hondt, E. (2015). Motor Competence and Its Effect on Positive Developmental Trajectories of Health. Sports Medicine, 45, 1273-1284.

https://doi.org/10.1007/s40279-015-0351-6

Sääkslahti, A., Numminen, P., Varstala, V., Helenius, H., Tammi, A., Viikari, J., \& Välimaki, I. (2004). Physical Activity as a Preventive Measure for Coronary Heart Disease Risk Factors in Early Childhood. Scandinavian Journal of Medicine and Science in Sports, 14, 143-149. https://doi.org/10.1111/j.1600-0838.2004.00347.x

Sallis, J. F., Prochaska, J. J., \& Taylor, W. C. (2000). A Review of Correlates of Physical Activity of Children and Adolescents. Medicine and Science in Sports and Exercise, 32, 963-975. https://doi.org/10.1097/00005768-200005000-00014

Smith, A. B. (2013). Understanding Children and Childhood (5th ed.). Wellington: Bridget Williams Books.

Smith, L. B., \& Thelen, E. (2003). Development as a Dynamic System. Trends in Cogni- 
tive Sciences, 7, 343-348. https://doi.org/10.1016/S1364-6613(03)00156-6

Stephenson, A. (1999). Images of Empowerment: The Outdoor Experiences of One Year Old Children. Early Childhood Folio, 4, 8-12.

Sugiyama, T., Okely, A. D., Masters, J. M., \& Moore, G. T. (2012). Attributes of Child Care Centers and Outdoor Play Areas Associated with Preschoolers Physical Activity and Sedentary Behavior. Environment and Behavior, 44, 334-339. https://doi.org/10.1177/0013916510393276

Thelen, E., Ulrich, B. D., \& Wolff, P. H. (1991). Hidden Skills: A Dynamic Systems Analysis of Treadmill Stepping during the First Year. Monographs of the Society for Research in Child Development, 56, i+iii+v-vi+1-103.

https://doi.org/10.2307/1166099

Timmons, B. W., Naylor, P. J., \& Pfeiffer, K. A. (2007). Physical Activity for Preschool Children-How Much and How? Applied Physiology, Nutrition and Metabolism, 32, S122-S134. https://doi.org/10.1139/H07-112

Valvano, J., \& Rapport, M. J. (2006). Activity-Focused Motor Interventions for Infants and Young Children with Neurological Conditions. Infant and Young Child, 19, 292307. https://doi.org/10.1097/00001163-200610000-00003

Wassenberg, R., Feron, F. J. M., Kessels, A. G. H., Hendrikse, J. G. M., Kalff, A. C., Kroes, M., \& Vles, J. S. H. (2005). Relation between Cognitive and Motor Performance in 5- to 6-Year-Old Children: Results from a Large-Scale Cross-Sectional Study. Child Development, 76, 1092-1103. https://doi.org/10.1111/j.1467-8624.2005.00899.x

Whitehead, M. (2010). The Concept of Physical Literacy. In M. Whitehead (Ed.), Physical Literacy throughout the Life Course (pp. 10-20). Abingdon, Oxford: Routledge.

Williams, J., \& Holley, P. (2013). Linking Motor Development in Infancy and Early Childhood to Later School Learning. The Australian Journal of Child and Family Health Nursing, 10, 15-21.

Wood, A., \& Johnson, M. (2013). Green Prescription Active Families Survey Report. Wellington: Ministry of Health. https://www.health.govt.nz/system/files/documents/topic sheets/grx-active-families-fi nal-report $0 . p d f$

Wrotniak, B. H., Epstein, L. H., Dorn, J. M., Jones, K. E., \& Kondilis, V. A. (2006). The Relationship between Motor Proficiency and Physical Activity in Children. Pediatrics, 118, 1758-1765. https://doi.org/10.1542/peds.2006-0742 
Submit or recommend next manuscript to SCIRP and we will provide best service for you:

Accepting pre-submission inquiries through Email, Facebook, LinkedIn, Twitter, etc. A wide selection of journals (inclusive of 9 subjects, more than 200 journals)

Providing 24-hour high-quality service

User-friendly online submission system

Fair and swift peer-review system

Efficient typesetting and proofreading procedure

Display of the result of downloads and visits, as well as the number of cited articles Maximum dissemination of your research work

Submit your manuscript at: http://papersubmission.scirp.org/

Or contact ape@scirp.org 